\title{
La dimensión teologal de las resistencias y luchas populares
}

\author{
Francisco de Aquino Júnior \\ Facultad Católica de Fortaleza y \\ Universidad Católica de Pernambuco
}

La teología de la liberación latinoamericana ha nacido y se ha desarrollado en el seno de las resistencias y las luchas populares. La participación de cristianos y comunidades cristianas en organizaciones y luchas populares ha obligado a la Iglesia a confrontar su compatibilidad con la fe cristiana y a explicitar el carácter estrictamente teologal o espiritual de dichas organizaciones y luchas. Este nuevo lugar social (resistencias, luchas y organizaciones populares) y esa nueva problemática (el carácter teologal de las resistencias y las luchas populares) ${ }^{1}$ han hecho posible desarrollar un quehacer teológico en consonancia con el núcleo de la experiencia bíblica de Dios: la parcialidad hacia los pobres y los marginados. Y no solo desde el punto de vista de lo urgente (asistencia inmediata), sino también desde el punto de vista estructural (estructuras de la sociedad). Así nacía y se desarrollaba lo que se ha convenido en llamar teología de la liberación, en sus diversas configuraciones - perspectivas, acentos, mediaciones, lenguajes, etc.

Para esas teologías, las resistencias, las luchas y las organizaciones populares no son un asunto o un tema más entre otros, sino que, además y más radicalmente, constituyen un aspecto esencial de la experiencia bíblica de Dios

1. La expresión teologal denota el carácter espiritual o salvífico de las resistencias y las luchas populares, independientemente de la intencionalidad y la conciencia. Ese carácter, real y objetivo, no se deriva de la conciencia, ni de la reflexión que se pueda o se deba hacer sobre él. No es la reflexión teológica la que hace que las resistencias y las luchas populares sean o tengan algo de salvífico o espiritual. Al contrario, la teología solo puede hablar del carácter espiritual o salvífico de esos procesos porque ellos, en sí mismos, no obstante sus limitaciones y sus ambigüedades, son o tienen algo de espiritual o de salvífico. 
(dimensión) y un lugar privilegiado para el quehacer teológico en su totalidad (perspectiva). Desde el comienzo, Gustavo Gutiérrez insistía en que la teología de la liberación, más que "un nuevo tema" para la reflexión, proponía una "nueva manera de hacer teología": "Una teología que no se limita a pensar el mundo, sino que busca situarse como un momento del proceso a través del cual el mundo es transformado: abriéndose [...] al don del reino de Dios"2. Esto solo se puede comprender en un contexto eclesial en el cual, como afirma Francisco Taborda, "la praxis histórica de la liberación" se convierte en el "trazo epocal de la fe". Ciertamente, "el trazo epocal no es el único trazo, ni siquiera el más frecuente, pero es el que mejor responde a los desafíos del momento"3, o, en todo caso, el que se confronta de modo más consecuente con el aspecto más determinante de la fe, en un determinado contexto.

Esto explica la importancia y la centralidad de las resistencias y las luchas populares en las más diversas teologías de la liberación, aun cuando estas no aborden directa y explícitamente la cuestión. Y esto justifica la importancia y la necesidad de retomar y tematizar el carácter teologal o espiritual de las resistencias y las luchas populares. Más aún, en un contexto histórico de exacerbación de las injusticias y las desigualdades y de crisis de esperanza, y en un contexto eclesial de aversión o indiferencia a los grandes problemas del mundo, a contracorriente del concilio Vaticano II y de la conferencia de Medellín, no obstante el empeño y la actuación profética del papa Francisco.

Lo que pretendemos aquí es retomar la problemática del carácter teologal de las resistencias y las luchas populares. A partir de la experiencia bíblica de Dios (revelación-fe), explicitaremos el carácter estrictamente teologal o espiritual de las resistencias y las luchas populares (salvación), así como su densidad y relevancia epistemológicas (teología).

\section{Experiencia bíblica de Dios}

Hablar del carácter teologal o espiritual de las resistencias y las luchas populares significa afirmar que tienen que ver con Dios y su designio salvífico para la humanidad (revelación), y, por tanto, con la relación o el vínculo con Él (fe). Significa mostrar cómo esas resistencias y luchas populares son parte de la historia de Dios con su pueblo. Significa explicitar sus potencialidades y sus ambigüedades salvíficas.

Para eso, tenemos que partir de la historia de Dios con su pueblo. Solo en esta historia, y a partir de ella, podemos hablar de Dios y de la relación con Él, aun

2. G. Gutiérrez, Teologia da libertação: Perspectivas, pp. 73s. (São Paulo: Loyola, 2000).

3. F. Taborda, Sacramentos, práxis e festa: Para uma teologia latino-americana dos sacramentos, p. 24 (Petrópolis: Vozes, 1994). 
cuando su misterio y su designio salvífico no se agoten en ninguna experiencia concreta. Dios es siempre mayor (trasciende). Pero es siempre mayor en esa historia (trasciende $e n$ ). Nunca hablamos de Dios sin más. Hablamos siempre de un Dios muy concreto y a partir de una experiencia muy concreta de Dios. Por más abstractos y universales que sean nuestros discursos, son siempre, de alguna manera, abstracciones y universalizaciones de una experiencia concreta, 0 , en todo caso, elaboraciones a partir de experiencias concretas. Y por más unidad que exista entre esas experiencias de Dios, solo podemos percibirla y articularla a partir de esas experiencias concretas.

En nuestro caso (tradición judeo-cristiana), hablamos de Dios a partir de su historia con Israel. Historia que alcanza su plenitud en Jesús de Nazaret, a quien confesamos como el Cristo de Dios. El discurso cristiano sobre Dios es inseparable de su presencia y su acción en la historia de Israel y en la vida de Jesús de Nazaret. A tal punto, que no se lo nombrará simplemente como Dios, sino como el Dios de Israel y como el Padre de Jesucristo ${ }^{4}$.

Ese Dios se manifiesta y se da a conocer como un Dios presente y actuante en la historia y como un Dios partidario de los pobres y los marginados (revelación). Y la relación con Él es una relación histórica, mediada por el compromiso con ellos (fe). De manera que, en sentido estricto, no podemos considerar cristiano ningún discurso sobre Dios o sobre la experiencia de Dios que prescinda y, menos aún, que se contraponga a su historicidad y parcialidad hacia los pobres y los marginados.

\subsection{La revelación}

El Dios judeo-cristiano es un Dios presente y actuante en la historia y un Dios que actúa en favor de los pobres y marginados. Estas son las dos características más importantes y decisivas de la revelación de Dios, en la historia de Israel y en la vida de Jesús de Nazaret ${ }^{5}$.

La Biblia no habla de Dios de manera abstracta y universal, sino de manera histórica. Narra la historia de Dios con su pueblo. Y esa historia no es una

4. Cfr. G. Gutiérrez, O Deus da vida (São Paulo: Loyola, 1992); R. Muñoz, O Deus dos cristãos (Petrópolis: Vozes, 1989); "Dios Padre", en I. Ellacuría y J. Sobrino, Mysterium liberationis. Conceptos fundamentales de la teología de la liberación, tomo II, pp. 531-549 (San Salvador: UCA Editores, 1994); y Trindade de Deus Amor oferecido em Jesus, o Cristo (São Paulo: Paulinas, 2002); A. González, Trinidad y liberación: la teología trinitaria considerada desde la perspectiva de la teología de la liberación (San Salvador: UCA Editores, 1994).

5. Cfr. J. Pixley, A história de Israel a partir dos pobres (Petrópolis: Vozes, 2002); X. Léon-Dufour, Agir segundo o evangelho: palavra de Deus (Petrópolis: Vozes, 2003); R. Fabris, A opção pelos pobres na Bíblia (São Paulo: Paulinas, 1991). 
historia cualquiera, sino una historia de salvación, en la cual Dios se manifiesta "como salvador, en la acción misma de salvar". Esta es la experiencia fundamental que nos transmite la Escritura. En el Antiguo Testamento, Dios libera al pueblo de la esclavitud y, en el contexto de esa liberación, se da a conocer: "en la acción misma de salvar a su pueblo, Dios dice quién es Él, y lo dice precisamente salvando"?. La revelación del nombre de Dios (Ex 3,14) es inseparable del éxodo y, por eso mismo, debemos leerla a partir y en función de él. En el Nuevo Testamento, la revelación de Dios es inseparable de la acción salvadora de Jesús: la Buena Noticia del reinado de Dios. La "palabra" que Dios ha comunicado (He 10,36 ), dice Pedro, no es otra cosa que "lo sucedido en toda Judea comenzando por Galilea" (He 10,37): "Dios ungió a Jesús de Nazaret con el Espíritu Santo, llenándolo de poder. Él pasó haciendo el bien y curando a todos los que habían caído en poder del demonio, porque Dios estaba con él" (He 10,38) ${ }^{8}$.

Por ser salvador, se manifiesta como un Dios partidario de los pobres y marginados, hasta el punto de identificarse con ellos (Mt 25,31-46). Como ha insistido Jon Sobrino:

la relación de Dios con los pobres de este mundo aparece como una constante en la revelación [...] la relación Dios-pobres en el Éxodo, en los profetas o en Jesús no es solamente coyuntural y pasajera, sino estructural. Existe una correlación trascendental entre revelación de Dios y clamor de los pobres ${ }^{9}$.

La liberación de los pobres y marginados en el éxodo y en la praxis de Jesús de Nazaret no es algo secundario o periférico en la revelación de Dios, sino algo constitutivo de esa revelación, algo que tiene que ver con el misterio más profundo de Dios. Revelarse en el proceso de liberación del éxodo (y no en el proceso de dominación del faraón) y en la praxis de Jesús de Nazaret (y no en la praxis del césar) no es un mero detalle, casualidad o ropaje, sino algo esencial, algo que tiene que ver con el misterio mismo de Dios, que no puede asumir la "forma" de un faraón o de un césar (tirano) sin negarse a sí mismo (Padre).

Esa experiencia de Dios narrada en la Escritura, además de ser la experiencia originaria de la tradición judeo-cristiana, constituye su criterio y su norma permanente. Claro que, en cuanto acontecimiento histórico, la revelación es un proceso vivo, dinámico y abierto. $\mathrm{Y}$ no solo en lo que respecta a su comprensión (siempre limitada...), sino, aún más radicalmente, en lo que respecta a su

6. A. González, Trinidad y liberación, op. cit., p. 59.

7. Ibidem.

8. Los textos bíblicos entre comillas están tomados de la versión digital de la Biblia Latinoamericana, disponible en http://www.sanpablo.es/biblia-latinoamericana/.

9. J. Sobrino, "Teología en un mundo sufriente. La teología de la liberación como 'intellectus amoris"', en El principio misericordia. Bajar de la cruz a los pueblos crucifcados, pp. 47-80, aquí p. 55 (Santander: Sal Terrae, 1992). 
realización histórica (siempre actual...). Es que Dios continúa actuando a través de su Espíritu. La revelación no es algo meramente pasado, sino algo muy actual. Y actual no solo como recuerdo, sino como realización histórica. Por eso, la teología no puede reducirse a una especie de arqueología salvífica. Es inteligencia de la acción salvífica de Dios hoy, a través de su Espíritu. De ahí la densidad teológica de lo presente, de los procesos históricos actuales.

Pero no se debe olvidar que el Espíritu de Dios, presente y actuante en la historia, no es otro que el Espíritu de Jesucristo. Su misión, como nos recuerda el evangelio de Juan, es enseñar y recordar todo lo que Jesús dijo (Jn 14,26), decir y explicar todo lo que oyó y recibió de Jesús (Jn 16,13-14), dar testimonio de Jesús (Jn 15,26). Así, pues, es inseparable de Jesús de Nazaret, a tal punto que, en la Escritura, su vida y su carne se toman como criterio fundamental y definitivo de discernimiento de los espíritus (1 Jn 4,1-3; 1 Cor 12,1-3): es de Dios si hace en nosotros lo que hizo en Jesús de Nazaret. El Espíritu Santo es el Espíritu de Jesús de Nazaret. El Espíritu que lo ungió, lo condujo y lo sostuvo en su misión de anunciar la Buena Noticia a los pobres (Lc 4,18s; He 10,38). No por casualidad la Iglesia invoca al Espíritu, en un himno muy antiguo, cantado en la Secuencia de Pentecostés, como "Padre de los pobres" (Veni pater pauperum). Y los estudios pneumatológicos latinoamericanos ${ }^{10}$ han insistido mucho en que "el Espíritu del Señor actúa desde abajo", para usar una expresión muy querida de Víctor Codina"

\subsection{La fe}

La fe es el acto por el cual nos adherimos confiada y fielmente al Dios que se ha revelado en la historia de Israel y definitivamente en la vida y la praxis de Jesús de Nazaret. De esa forma, la fe está constitutivamente referida, determinada y configurada por la manera de ser y de actuar de ese Dios, en la historia de Israel y en la praxis de Jesús de Nazaret. La fe cristiana solo es comprensible si parte y está en función del Dios de Israel y de Jesús de Nazaret. Esta fe es respuesta a la

10. Cfr. J. Pixley, Vida no espírito. O projeto messiânico de Jesus depois da ressureição (Petrópolis: Vozes, 1997); V. Codina, Creio no Espírito Santo. Pneumatologia narrativa (São Paulo: Paulinas, 1997); "Não extingais o Espirito" (1 Ts 1,19): Iniciação à pneumatologia (São Paulo: Paulinas, 2010); y El Espíritu del Señor actúa desde abajo (Santander: Sal Tarrae, 2015); J. Comblin, O Espírito Santo e a Tradição de Jesus. Obra póstuma (São Bernado do Campo: Nhanduti, 2012); L. Boff, $O$ Espírito Santo: Fogo interior, doador de vida e Pai dos pobres (Petrópolis: Vozes, 2013); A. Manzatto, J. D. Passos y J. F. Monnerat, A força dos pequenos. Teologia do Espirito Santo (São Paulo: Paulus, 2013).

11. "La acción del Espíritu desde abajo está en perfecta coherencia con la opción de Jesús por los pobres y pequeños, con el designio del Padre de hacer de ellos los destinatarios privilegiados de la revelación de los misterios del reino" (V. Codina, El Espíritu del Señor actúa desde abajo, op. cit., p. 187. 
propuesta de ese Dios. La iniciativa es suya (propuesta). Sin embargo, para que se haga real y efectiva, es necesario que sea asumida por cada uno de nosotros (respuesta). En este sentido, la fe es, sin duda, un "don" (Ef 2,8), pero un don que, una vez acogido, nos re-crea, insertándonos en su propio dinamismo: "Lo que somos es obra de Dios: hemos sido creados en Cristo Jesús con miras a las buenas obras que Dios dispuso de antemano para que nos ocupáramos en ellas" (Ef 2,10). Es, por tanto, un don-tarea: algo que recibimos para realizar.

La fe, en cuanto tal, tiene un dinamismo fundamentalmente práctico. Es una dinámica de vida, una manera de vivir: vivir como Jesús vivió. Es seguimiento de Jesús de Nazaret, el autor y consumador de la fe (Heb 12,2) ${ }^{12}$. Ciertamente, la fe es un acto inteligente y tiene su momento de verdad. Pero no es pura intelección, ni esa intelección es, sin más, una doctrina conceptualmente bien elaborada. Y ciertamente, también tiene una expresión simbólico-ritual. Pero esta expresión no es otra cosa que una manifestación, más o menos adecuada y eficaz, del seguimiento de Jesús de Nazaret. No tratamos de contraponer el carácter práxico de la fe con sus momentos de verdad y teoría, y de expresión simbólico-ritual. Solamente tratamos de llamar la atención acerca del peligro de caer en la reducción intelectualista o ritualista. La fe debe ser comprendida y asumida en su totalidad y en sus diversas dimensiones (itambién la intelectual y litúrgica!) como praxis del seguimiento de Jesús de Nazaret.

La insistencia en el carácter práxico de la fe no pone en peligro el primado de la gracia. En consecuencia, tampoco cae en la tentación de la autosuficiencia y la autosalvación humana, como si la salvación fuese fruto de nuestra actividad (individual o colectiva), antes que un don gratuito de Dios. No debemos olvidar que si nosotros amamos, es porque "él nos amó primero" (1 Jn 4,19), y que "el amor viene de Dios" (1 Jn 4,7). No existe contradicción entre la acción de Dios y la acción humana. Una no implica la negación de la otra. Al contrario, ambas se implican y se remiten mutuamente. Como afirma Sobrino, "ha sido un error frecuente situar la experiencia de la gratuidad en lo que recibimos, como si la acción fuere meramente 'obra' del hombre". En verdad, "el don se experimenta en la propia donación"13. En la formulación de Antonio González, "la acción

12. Cfr. V. Codina, "Fe en Cristo y opción por los pobres", en Una Iglesia Nazarena: Teología desde los insignificantes, pp. 29-43 (Santander: Sal Tarrae, 2010); J. Sobrino, "Seguimento de Jesus", en C. Floristán Samanes y J. J. Tamayo-Acosta, Dicionário de Conceitos Fundamentais do Cristianismo, pp. 771-775 (São Paulo: Paulus, 1999); V. I. Bambonatto, Seguimento de Jesus: Uma abordagem segundo a cristologia de Jon Sobrino (São Paulo: Paulinas, 2002); cátedra Chaminade, El seguimiento de Jesús (Madrid: Fundación Santa María, 2004); F. Aquino Júnior, "A fé como seguimento de Jesus Cristo", REB 292 (2013), 788-815.

13. J. Sobrino, Cristología desde América Latina: Esbozo a partir del seguimiento del Jesús histórico, p. 193 (México D. F.: CRT, 1977). 
humana no es, sin más, 'obra' del hombre, sino que 'el don se experimenta en la propia donación', en cuanto fundamento de la misma. De modo que la fe es actividad humana en cuanto entrega a Dios como fundamento de la propia vida"|4.

Esa entrega a Dios significa, concretamente, configurar la vida de acuerdo con Él y colaborar en su actuación histórica en favor de los pobres y marginados. La entrega a Dios siempre está mediada por la participación en su acción salvífica en el mundo (historicidad), una acción a favor de los pobres y marginados (parcialidad). Como bien afirma el papa Francisco, "existe un vínculo inseparable entre nuestra fe y los pobres" $(E G, 48)$. "Todo el camino de nuestra redención está signado por los pobres" $(E G, 197)$. Fuera del dinamismo salvífico en favor de los pobres y marginados, no se puede hablar propiamente de fe cristiana, puesto que esta no puede ser vivida ni pensada de manera independiente, y mucho menos contrapuesta, al dinamismo salvífico de Dios, que se historizó en Israel y, de manera definitiva, en la vida de Jesús de Nazaret. Aquí se comprende perfectamente la insistencia profética de Sobrino de que "fuera de los pobres no hay salvación"15. Al fin y al cabo, si la fe es entrega a un Dios salvador de los pobres y marginados, nos inserta necesariamente en su dinamismo salvífico a favor de ellos. A tal punto, que esto se convierte en signo, criterio y medida de la fe ( $c f r$. Mt 25,31-46; Lc 10,25-37). Por los frutos se conoce el árbol (cfr. Lc 6,44).

Revelación y fe constituyen dos aspectos del proceso de realización histórica de la salvación. Aspectos que se remiten y se implican mutuamente. Aquí se encuentra en juego la realización histórica de la salvación. Un acontecimiento que se va realizando en procesos de liberación: Israel, en Egipto y en Babilonia; pobre, huérfano, viuda y extranjero, en Israel. Y aquí siempre están implicados Dios y el pueblo. Dios se revela como salvador, en el acto mismo de salvar a su pueblo: Dios de Israel, Dios de los pobres y marginados. Y en la medida en que el pueblo acoge a ese Dios y va construyendo su vida en comunión con Él, se constituye como su pueblo: pueblo de Dios. En esto consiste la experiencia de Dios que nos narran las Escrituras. Ella constituye el corazón de la Torá, de la actuación de los profetas, de la sabiduría de Israel y de la vida y misión de Jesús de Nazaret y de sus comunidades.

Si hay algo en la Sagrada Escritura que no se puede negar ni ocultar, es la centralidad de los pobres y oprimidos en la historia de la salvación. Dios aparece (revelación) como go'el, que rescata a sus parientes de la esclavitud, como pastor que apacienta a las ovejas, como rey que hace justicia a los pobres y oprimidos, como padre que cuida de sus hijos y los socorre en sus necesidades. Y la relación

14. A. González, Trinidad y liberación, op. cit., pp. 68s. Cfr. X. Zubiri, El hombre y Dios, pp. 210-222 (Madrid: Alianza Editorial, 2003).

15. J. Sobrino, Fuera de los pobres no hay salvación: Pequeños ensayos utópico-proféticos (Madrid: Trotta, 2007). 
con Él (fe) pasa siempre por la observancia y la defensa del derecho del pobre y del oprimido, por la proximidad con el caído a la orilla del camino. Todas las imágenes y metáforas que usa la Escritura para hablar de la acción de Dios y de la interacción entre Dios y su pueblo (go'el, pastor, rey, padre, etc.) revelan la centralidad de los pobres y marginados, expresada en el cuarteto "pobrehuérfano-viuda-extranjero". El exegeta alemán Joachim Jeremias ha insistido mucho en que el "rasgo decisivo" del reinado de Dios, centro y resumen de la predicación de Jesús, consiste en la "oferta de la salvación hecha por Jesús a los pobres"16. De modo que la salvación de los pobres y marginados constituye el corazón de la historia de Dios con su pueblo. Hasta el punto de convertirse en criterio y medida de fidelidad a la alianza de Dios con Israel y de adhesión o rechazo al reinado de Dios anunciado por Jesús de Nazaret.

\section{Carácter salvífico de las resistencias y luchas populares}

La recuperación de la experiencia bíblica de Dios (realización histórica de la salvación) es lo que ha permitido a la Iglesia latinoamericana comprender la densidad y la relevancia teologal o espiritual de las resistencias y las luchas populares: percibir en las resistencias y en los procesos históricos de liberación la presencia y la acción salvífica de Dios, un signo del Espíritu, que actúa desde abajo. Medellín es muy claro a este respecto:

Así como otrora Israel, el primer Pueblo de Dios, experimentaba la presencia salvífica de Dios cuando lo liberaba de la opresión de Egipto, cuando lo hacía pasar el mar y lo conducía hacia la tierra de la promesa, así también nosotros, nuevo pueblo de Dios, no podemos dejar de sentir su paso que salva, cuando se da "El verdadero desarrollo, que es para cada uno y para todos, el paso de condiciones de vida menos humanas, a condiciones más humanas"17.

Es verdad que la Iglesia no percibió eso ella sola, ni por sí misma. La Iglesia fue provocada por los movimientos sociopolíticos de liberación. Fueron ellos los que recogieron los clamores del pueblo y los articularon en diversas organizaciones y luchas sociales, en las regiones más diversas del continente. Pero también es verdad que solo a medida que la Iglesia ha ido descubriendo que la experiencia bíblica de Dios es fundamentalmente una experiencia histórica de liberación de las más diversas formas de injusticia, de opresión y de marginación, ha podido percibir y comprender la densidad teológica de los procesos históricos de liberación. Es que, como advierte Ignacio Ellacuría, "origen" y "principio" no son lo mismo y "no todo origen se convierte en principio". Por más que los movi-

16. J. Jeremias, Teologia do Novo Testamento, p. 176 (São Paulo: Hagnos, 2008).

17. Celam, Conclusões de Medellín, p. 7 (São Paulo: Paulinas, 1987). Véase también "Medellín (1968). Disponible en http://www.diocese-braga.pt/catequese/sim/biblioteca/publicacoes online/91/medellin.pdf, 6 . 
mientos y las organizaciones sociales hayan despertado y convocado a la Iglesia a colaborar con los procesos históricos de liberación (origen), esta solo pudo ser asumida por aquella porque dicha liberación constituye "la esencia misma del mensaje revelado, del don salvífico de Dios a los hombres" (principio) ${ }^{18}$.

Y también es verdad que eso no ocurre en la Iglesia de un momento a otro, como por arte de magia. Ha sido preparado por un largo proceso de renovación teológico-pastoral, que culminó en el concilio Vaticano II, y se ha desarrollado en el proceso de recepción eclesial, sobre todo, en América Latina. Conviene destacar aquí dos aspectos de ese proceso de renovación eclesial. Son dos aspectos decisivos para la percepción de la densidad espiritual de los procesos históricos de liberación.

El primero es el esfuerzo para superar el dualismo natural-sobrenatural, que ha dominado la reflexión teológica durante siglos ${ }^{19}$. Al querer "salvar" la gratuidad de la salvación, este dualismo compromete el carácter creatural y gracioso del mundo, hace irrelevante su salvación y debilita el compromiso de la Iglesia con su transformación. De ahí que el concilio comprenda la Iglesia como signo e instrumento de la salvación del mundo ( $c f r . L G, 1,9,48)$ y afirme que

El divorcio entre la fe y la vida diaria de muchos debe ser considerado como uno de los más graves errores de nuestra época. [...] No se creen, por consiguiente, oposiciones artificiales entre las ocupaciones profesionales y sociales, por una parte, y la vida religiosa, por otra. El cristiano que falta a sus obligaciones temporales, falta a sus deberes con el prójimo; falta, sobre todo, a sus obligaciones para con Dios y pone en peligro su eterna salvación ${ }^{20}$ $(G S, 43)$.

El segundo aspecto es el re-descubrimiento de la universalidad de la salvación, que extrapola los límites visibles de la Iglesia. En efecto, la salvación muchas veces se realiza por caminos que desconocemos ( $c f r . N A ; L G, 16$ ). Esto lleva a que el concilio afirme que "la Iglesia católica no rechaza nada de lo que en [otras] religiones haya de santo y verdadero", a que reconozca que ellas "reflejan un destello de aquella Verdad que ilumina a todos los hombres" y a que exhorte a todos a que "reconozcan, guarden y promuevan aquellos bienes espirituales y morales, así como los valores socio-culturales que en ellas existen" $(N A, 2)$. El

18. Cfr. I. Ellacuría, "En torno al concepto y a la idea de liberación", en Escritos teológicos, I, pp. 629-657, aquí pp. 631 y 629, respectivamente (San Salvador: UCA Editores, 2000).

19. Cfr. L. Ladaria, "Natural e sobrenatural", en B. Sesboüé (ed.), História dos dogmas, tomo 2: O homem e sua salvação, pp. 313-343 (Sāo Paulo: Loyola, 2003).

20. Cfr. Constitución pastoral Gaudium et spes, sobre la Iglesia en el mundo actual. Disponible en http://www.vatican.va/archive/hist councils/ii vatican council/documents/vat-ii const 19651207 gaudium-et-spes sp.html, 43. 
concilio llega incluso a afirmar que "no podemos invocar a Dios, Padre de todos, si nos negamos a conducirnos fraternalmente con algunos hombres, creados a imagen de Dios" $(N A, 5)$. Esto será fundamental y decisivo para percibir la salvación fuera de la Iglesia.

Nada de eso compromete o niega la gran novedad que se ha dado en la Iglesia latinoamericana, la cual consiste en el descubrimiento de la densidad espiritual de los procesos históricos de liberación. No se trata únicamente de la participación de cristianos en los procesos históricos de liberación - a pesar de su fe. No se trata solo de una comprensión histórico-abstracta de la salvación y de una abertura genérica al mundo. Se trata, primaria y radicalmente, de retomar el sentido bíblico de la salvación, que se realiza en procesos históricos de liberación, y de asumir esos procesos, no a pesar de la fe, sino precisamente en la fe y motivados por la fe. La historicidad de la salvación se materializa en procesos históricos de liberación. De ahí su carácter salvífico, no obstante sus límites y sus ambigüedades. De ahí la importancia y la centralidad de esos procesos en la vivencia de la fe, particularmente en un contexto como el nuestro, marcado por tan profundas injusticias, opresiones y marginaciones.

El re-descubrimiento y la explicitación del carácter salvífico de los procesos históricos de liberación y de su importancia y centralidad para la vivencia de la fe fueron, sin ninguna duda, dos de los aportes más importantes, si no los más importantes, de la Iglesia latinoamericana, tanto en su acción pastoral como en su reflexión teológica.

Desde el punto de vista de la acción pastoral, ha confirmado y llevado a miles de cristianos a comprometerse en los procesos de liberación, a través de las más diversas luchas y organizaciones populares, en todo el continente. Cientos de cristianos, entre los cuales encontramos a muchos sacerdotes e incluso obispos, han llegado a dar la vida en esos procesos. Son mártires de la justicia del reino. Esto ha hecho que la Iglesia latinoamericana no solo sea sensible, sino que también se comprometa con los pobres y con la lucha por la justicia, en lo que se ha convenido en llamar "la opción preferencial por los pobres", "uno de los rasgos que marca la fisonomía de la Iglesia latinoamericana y caribeña" (Aparecida, 391).

Desde la reflexión teológica, la conciencia y el desarrollo de esa problemática han ido creando, en medio de tensiones y ambigüedades, algunos consensos teológicos fundamentales ${ }^{21}$ : la superación de los dualismos natural-sobrenatural

21. Cfr. G. Gutiérrez, Teologia da libertação, op. cit., pp. 195-363; L. Boff, Teologia do cativeiro e da libertação, pp. 73-102 (Petrópolis: Vozes, 1980); L. Boff y C. Boff, Da libertação: O teológico das libertações sócio-históricas (Petrópolis: Vozes, 1980); J. L. Segundo, "Libertad y liberación", en I. Ellacuría y J. Sobrino, Mysterium liberationis: Conceptos fundamentales de la teología de la liberación, tomo I, pp. 
y profano-sagrado; la historicidad de la salvación; la salvación como liberación; la liberación integral; la necesidad de mediaciones históricas para la salvación y la liberación, no obstante sus límites y ambigüedades; la tensión escatológica entre el "ya" y el "todavía no" de la salvación y la liberación; y los pobres como "lugar teológico". Es verdad que estos consensos teológicos fundamentales fueron, en buena medida, más intuidos y esbozados que desarrollados ${ }^{22}$. Es verdad también, como reconoce Juan Luis Segundo, que fueron asumidos muy rápidamente como presupuestos evidentes y aceptados por la Iglesia, lo cual dispensaba de mayores investigaciones y desarrollos ${ }^{23}$. En todo caso, esos consensos fueron decisivos para la comprensión y explicitación del carácter teologal o espiritual de las resistencias, de las luchas y de las organizaciones populares.

El carácter teologal o espiritual de las resistencias, las luchas y las organizaciones populares posee dos aspectos fundamentales mutuamente implicados. Por un lado, denuncian y se enfrentan con las "estructuras de pecado", que continúan matando hijos e hijas de Dios en este mundo, o sea, con los mecanismos económicos, políticos, jurídicos, culturales, religiosos, etc., que niegan las condiciones materiales de vida a gran parte de la población, que oprimen y marginan a amplios sectores de la sociedad y que legitiman las más diversas formas de injusticia, de opresión y de marginación. Aquello que desde Medellín y Puebla se ha convenido en llamar "estructuras de pecado", "pecado estructural" o "pecado social".

Por otro lado, estas resistencias, luchas y organizaciones se constituyen en "mediadoras de la salvación", en la medida que buscan y ensayan alternativas de vida y sobrevivencia, en medio de la miseria, la injusticia y la marginación, y en la medida que buscan también nuevas formas y nuevos mecanismos de organización social, que garanticen los derechos de los sectores empobrecidos y marginados, más allá de su afirmación formal. Y eso, independientemente de su

373-391 (Madrid: Trotta, 1994); I. Ellacuría, "El desafío cristiano de la teología de la liberación", en Escritos teológicos, I, op. cit., pp. 19-33; "Los pobres, "lugar teológico' en América Latina", op. cit., pp. 139-161; "Historia de la salvación", op. cit., pp. 597-628; "En torno al concepto y a la idea de liberación", op. cit., pp. 629-657; y "La Iglesia de los pobres, sacramento histórico de liberación", en Escritos teológicos, II, pp. 453-485 (San Salvador: UCA Editores, 2000).

22. Cfr. G. Gutiérrez, Teologia da libertaçâo, op. cit., pp. 196 y 197.

23. "La teología de la liberación no ha insistido lo bastante en el fundamento teológico de esa vuelta [a lo humano] exigida por el concilio. La teología de la liberación ha seguido como si aquella vuelta hubiera tenido lugar y hubiera sido aceptada por la Iglesia entera y, de un modo especial, por la jerarquía que la había firmado por abrumadora mayoría" (J. L. Segundo, "Críticas y autocríticas de la teología de la liberación", en J. Comblin, J. I. González Faus y J. Sobrino, Cambio social y pensamiento cristiano en América Latina, pp. 215-236, aquí p. 219 (Madrid: Trotta, 1993). 
vínculo religioso y eclesial, de la conciencia del carácter salvífico de su acción y de los límites y las ambigüedades de dicha acción ${ }^{24}$.

Se trata de la denuncia y del enfrentamiento del pecado, en su dimensión socio-estructural -pecado cristalizado en estructuras sociales, y mediado por ellas-, y de la realización de la salvación, en su dimensión socio-estructural, o sea, del esfuerzo de organización de la sociedad, de acuerdo con el espíritu evangélico, cuyo criterio y medida permanente son los derechos de los pobres y marginados - la mediación de la salvación por las estructuras sociales.

La afirmación del carácter teologal o espiritual de las resistencias, las luchas y las organizaciones populares, en su doble dimensión de denuncia y enfrentamiento del pecado socio-estructural y de ensayo y mediación socio-estructural de la salvación, no quiere decir absolutización de dichas resistencias, luchas y organizaciones, ni negación de las ambigüedades y contradicciones existentes en ellas - dónde no hay ambigüedades y contradicciones. No constituyen la salvación o el reinado de Dios sin más y en su plenitud, como tampoco lo es ningún proceso histórico social o eclesial. Pero son signos y mediaciones históricas de la salvación o del reinado de Dios en este mundo. Signos y mediaciones limitados, ambiguos y contradictorios, pero reales y verdaderos.

En palabras de Leonardo Boff, "las liberaciones históricas son [...] anticipaciones y concreciones, siempre limitadas, pero reales, de la salvación que será plena solamente en la eternidad"; entre el "reino de Dios y [1a] sociedad justa" existe una "identificación" - se identifica en-, pero no una "identidad" - no se identifica $\operatorname{con}^{25}$. En palabras de Gustavo Gutiérrez:

El crecimiento del reino es un proceso que se da históricamente en la liberación, [...] pero no se agota en ella; realizándose en hechos históricos liberadores, denuncia sus límites y ambigüedades, anuncia su cumplimiento pleno y lo impulsa efectivamente a la comunión total [...] Es más, puede decirse que el hecho histórico, político, liberador es crecimiento del reino, es acontecer salvífico, pero no es la llegada del reino, ni toda la salvación ${ }^{26}$.

Naturalmente, la salvación o el reinado de Dios no se pueden reducir a su dimensión social, ni la dimensión social de la salvación o del reinado de Dios puede reducirse a los procesos organizados de lucha para la transformación de las estructuras de la sociedad. La salvación o el reinado de Dios tienen que ver con todas las dimensiones de la vida humana (personal, social e histórica) y con

24. Cfr. F. Aquino Júnior, "Fé-política: uma abordagem teológica", en $A$ dimensão socioestrutural do reinado de Deus: Escritos de teologia social, pp. 173-195 (São Paulo: Paulinas, 2011).

25. L. Boff y C. Boff, Da libertação, op. cit., pp. 26 y 58.

26. G. Gutiérrez, Teologia da libertação, op. cit., p. 237. 
la totalidad de la creación (cosmos); se realizan en la historia, pero abriendo y trascendiendo la historia, más allá de sus límites espacio-temporales (trascendencia en la historia). La dimensión social de la salvación o del reinado de Dios tiene que ver con la diversidad de formas y niveles del vínculo social: relaciones interpersonales (familia, comunidad, conocidos, asociaciones, etc.) y relaciones impersonales o estructurales (costumbres, normas, leyes, estructuras económicas, políticas, etc. $)^{27}$. La lucha por la justicia y por la transformación de la sociedad es, incluso, mucho más amplia y compleja que los movimientos y las organizaciones populares. Sea porque tiene muchas dimensiones y necesita ser asumida y mediada por muchos grupos y sectores sociales. Sea porque está enraizada en procesos más básicos y sutiles de resistencia popular: la lucha cotidiana por la vida y la solidaridad primaria, vivida en situaciones límite ${ }^{28}$. Lo que Sobrino llama "santidad primordial" 29 .

Es también evidente que los procesos históricos de liberación (resistencias, luchas y organizaciones populares) no son puros ni perfectos. Son limitados, ambiguos y contradictorios. Tienen sus pecados: reduccionismo, cerrazón, autoritarismo, sectarismo, centralismo, personalismo, violencia, corrupción, machismo, racismo, homofobia, antropocentrismo, falta de respeto y agresión a los propios compañeros, entre otros. Y es necesario purificarlos, alargarlos y dinamizarlos con la luz y la fuerza del evangelio. El reconocimiento de su densidad teologal o espiritual no puede ocultar, ni comprometer la necesidad de conversión y la llamada a la misma, incluso para no comprometer todavía más su densidad espiritual, sino para intensificarla.

27. Cfr. F. Aquino Júnior, "A dimensão social da fé", en A dimensão socioestrutural do reinado de Deus, op. cit., pp. 15-28.

28. Cfr. F. Aquino Júnior, “Tudo tem jeito. Só não tem jeito para a morte'. A esperança que vem das ruas e dos lixões", en A dimensâo socioestrutural do reinado de Deus, op. cit., pp. 197-212; y "Entre ruas: fé e esperança de um povo. Espiritualidade da Pastoral do Povo da Rua", en Viver segundo o espírito de Jesus Cristo. Espiritualidade como seguimento, pp. $47-58$ (São Paulo: Paulinas).

29. J. Sobrino, Terremoto, terrorismo, barbarie y utopia: El Salvador, Nueva York, Afganistán, pp. 35-37, 125-135 (Madrid: Trotta, 2002). "En la decisión primaria de vivir y dar vida [...] se hace presente una como santidad primordial"; "el anhelo de vivir y sobrevivir en medio de grandes sufrimientos, la decisión y los trabajos para lograrlo, con creatividad sin límites, con fortaleza, con constancia, desafiando innumerables dificultades y obstáculos, es lo que llamamos de santidad primordial. Ellos, pobres y víctimas - mujeres, sobre todo, con sus hijos-, aun en medio de la catástrofe y en el imposible día a día, cumplen insignemente y ponen en práctica la llamada de Dios a vivir y a dar vida a otros"; "es la santidad del sufrimiento por querer vivir, que tiene una lógica distinta, pero más primaria, que la santidad de la virtud y que la santidad política" (ibid., pp. 125-126). 
Vale la pena recordar aquí la tercera carta pastoral de Mons. Romero, titulada La Iglesia y las organizaciones políticas populares ${ }^{30}$, publicada el 6 de agosto de 1978. Al tratar de las "relaciones entre la Iglesia y las organizaciones populares", el arzobispo hace una doble consideración. A nivel práctico, "todo depende de la situación histórica real". A nivel teórico, es preciso considerar "tres principios" fundamentales: "la naturaleza propia de la Iglesia", "la Iglesia al servicio del pueblo" y la "inserción de los esfuerzos liberadores en la salvación cristiana". En el contexto de la explicación de esos principios, Mons. Romero hace algunas afirmaciones decisivas respecto a la densidad teologal o espiritual de las luchas y las organizaciones populares y a la relación de la Iglesia con esas mismas luchas y organizaciones populares.

- La misión propia que Cristo confió a su Iglesia no es de orden político, económico o social. El fin que le asignó es de orden religioso. Pero precisamente de esta misma misión religiosa derivan funciones, luces y energías que pueden servir para establecer y consolidar la comunidad humana según la ley divina (52).

- A la Iglesia le compete recoger todo lo que de humano haya en la causa y lucha del Pueblo, sobre todo de los pobres. La Iglesia se identifica con la causa de los pobres cuando éstos exigen sus legítimos derechos (63).

- Esta solidaridad con los objetivos justos no está condicionada a determinadas organizaciones. Llámense cristianas o no, estén protegidas, legal o realmente, por el gobierno o sean independientes u opuestas a él, a la Iglesia solo le interesa una condición: que el objetivo de la lucha sea justo para apoyarlo desde la fuerza de su Evangelio. Así como también denunciar con sincera imparcialidad lo que es injusto en cualquier organización donde se detecte (64).

- La Iglesia, hemos dicho, alienta y fomenta los anhelos justos de organización y apoya, en lo que tienen de justo, sus reivindicaciones. Pero no estaría completo el servicio de la Iglesia a estos esfuerzos legítimos de liberación si no los iluminara con la luz de su fe y de su esperanza cristiana, enmarcándolos en el designio global de la salvación operada por el Redentor Jesucristo (70).

- Si la Iglesia, por apoyar a cualquier grupo en sus esfuerzos de liberación temporal, perdiera esta perspectiva global de la salvación cristiana, entonces "la Iglesia perdería su significación más profunda, su mensaje de liberación no tendría ninguna originalidad y se prestaría a ser acaparado

30. Cfr. Mons. Ó. A. Romero y Mons. A. Rivera, "La Iglesia y las organizaciones políticas populares", en Centro Monseñor Romero, Cartas pastorales y discursos de Monseñor Óscar A. Romero, pp. 67-105 (San Salvador: UCA Editores, 2007). 
y manipulado... no tendría autoridad para anunciar, de parte de Dios, la liberación" [EN, 32] (72).

Esto demuestra la complejidad del carácter teologal o espiritual de las luchas y las organizaciones populares. Debemos considerarlas tanto en lo que tienen de mediación positiva de la salvación o del reinado de Dios en este mundo, como desde sus límites, ambigüedades y contradicciones, en relación con la realización histórica de la salvación o del reinado de Dios. Aquí, en todo caso, hemos querido explicitar su carácter salvífico, sin reducir la salvación a su dimensión socioestructural, ni negar las ambigüedades y contradicciones salvíficas ahí presentes.

\section{Densidad y relevancia epistemológica de las resistencias y las luchas populares}

La teología es inteligencia de la fe al servicio de la fe. Es un esfuerzo intelectivo de aprehensión, explicitación y elaboración sapiencial-teórica de la fe. Este esfuerzo está siempre al servicio de la vivencia y del fortalecimiento de esa misma fe. De modo que la teología se configura y se desarrolla en un doble movimiento: de la vivencia de la fe a la inteligencia de la fe y de la inteligencia de la fe a la vivencia de la fe. De una u otra forma, siempre es un momento de la fe: momento intelectivo y momento iluminador. Sin fe no hay teología (inteligencia de la fe) y sin fe la teología es un discurso ineficaz e inútil (servicio a la fe) ${ }^{31}$.

Es verdad que el desarrollo de la inteligencia de la fe puede exigir, y de hecho exige, cierto distanciamiento de la experiencia inmediata. El quehacer teológico, en cuanto actividad intelectiva, tiene exigencias, dinamismos y un aparato teórico (hábitos, métodos, capacidades, conocimientos, etc.), que le proporcionan cierta autonomía en relación a la vivencia inmediata de la fe. Ese distanciamiento es importante incluso para ayudar a la comunidad eclesial a ensanchar los horizontes de la fe y a evitar o superar posibles desviaciones e instrumentalizaciones de la fe. Pero eso no significa ni puede llevar jamás a una separación e independencia total del quehacer teológico con relación a la fe. Siempre que eso acontece, la teología pierde su vitalidad, se hace arqueología, se convierte en un discurso religioso ineficaz e inútil, por más erudito y progresista que sea o parezca. En palabras más precisas y rigurosas de Ignacio Ellacuría, "deja de ser un intellectus fidei para ser un estudio de inoperatividades" 32 . Y

31. Cfr. G. Gutiérrez, A verdade vos libertará: Confrontos, pp. 19-21 (São Paulo: Loyola, 2000); Beber no próprio poço: Itinerário espiritual de um povo, pp. 49-52 (Petrópolis: Vozes, 1984); I. Ellacuría, "Relación teoría y praxis en la teología de la liberación", en Escritos teológicos, I, op. cit., pp. 235-245; U. Vázquez Moro, "Padecer e saber", Perspectiva Teológica 48, sup. 1 (2016), 13-17.

32. I. Ellacuría, "Relación teoría y praxis en la teología de la liberación", op. cit., pp. 235-245, aquí pp. 241s. 
esa es una tentación permanente del quehacer teológico: refugiarse en textos y erudiciones academicistas, abandonando la realidad concreta, donde Dios se hace presente y actúa.

Uno de los grandes méritos de la teología de la liberación ha sido enfrentarse teológicamente con los procesos históricos, y discernir allí los signos y las llamadas de Dios a su pueblo. De esa manera, ayudó a la comunidad eclesial a comprometerse con esos procesos, a partir y en función de los pobres y marginados, colaborando, así, con la realización histórica de la salvación y del reinado de Dios. Eso ha dado vitalidad al quehacer teológico en América Latina y lo ha hecho más consecuente, desde el punto de vista teórico (momento de la praxis) y teológico (momento consciente y reflejo de la realización histórica de la salvación y del reinado de Dios). Más que un estudio de textos y doctrinas, la teología se ha ido desarrollando como aquello que debe ser: inteligencia de la fe al servicio de la fe, en un contexto marcado por profundas desigualdades e injusticias sociales. Naturalmente, el desarrollo de la inteligencia de la fe implica, como uno de sus momentos constitutivos fundamentales, el estudio de la Escritura y de toda la tradición eclesial. Pero como un momento del proceso mayor de inteligencia de la fe real y concreta de la comunidad eclesial, en un contexto muy determinado.

Desde el punto de vista epistemológico, esto ha tenido como consecuencia, más allá del nivel de la conciencia y la elaboración teórica, el primado de lo real (la salvación) sobre lo teórico (la doctrina de la salvación) ${ }^{33}$. Esto implica concebir la teología, no siempre de manera consciente y elaborada, como momento intelectivo de la realidad y de la realización de la salvación. No obstante, la tentación de apartarse de la realidad y de refugiarse en el academicismo teórico más o menos estéril e ineficaz es enorme, sobre todo, en un contexto social y eclesial adverso, como el que hemos vivido en las últimas décadas. No pocos teólogos han cedido de alguna manera a esa tentación en América Latina. Han continuado haciendo teología progresista e incluso defendiendo a la teología de la liberación, pero sin ocuparse ya de los procesos históricos de liberación. Tenían cosas o temas más interesantes y atractivos en qué ocuparse, que la vida y las luchas del pueblo... Hasta los debates y la insistencia en la dimensión pública de la teología - un tema, o, por lo menos, un concepto de moda- parecen estar más vinculados, cuando no reducidos, al ámbito teórico-cultural que a los procesos históricos de liberación. Esto, irónicamente, termina comprometiendo la eficacia pública de la teología. Es el peligro, jreal y actual!, de reducir la teología a un "discurso del discurso" o a una "teoría de la teoría", sin incidencia real y efectiva en los procesos históricos de liberación. De esta manera, se compromete la densidad y

33. Cfr. A. González, Trinidad y liberación, op. cit., pp. 50-74; F. Aquino Júnior, "Questões fundamentais de teologia da libertação", Perspectiva Teológica 48 (2016), 245-268, aquí pp. 254-257. 
la relevancia de la teología, tanto en lo que tiene de teórico (momento intelectivo de la praxis) como en lo que tiene de teológico (inteligencia de la realización histórica de la salvación o del reinado de Dios y del servicio al mismo). Es lo que Sobrino llama la "tendencia al docetismo" en la teología actual.

En 2000, la Sociedad de Teología y Ciencias de la Religión del Brasil (Soter) realizó un congreso continental para conmemorar los treinta años de teología en América Latina. El congreso trató de los problemas y retos del mundo actual y de las perspectivas que se abrían al comenzar el nuevo milenio. Se pidió a varios teólogos que hicieran memoria de esos treinta años y de su trayectoria personal a lo largo de ellos, y que identificaran algunos retos actuales para la teología.

Sobrino escribió un texto autobiográfico, titulado “Teología desde la realidad", que concluye con "algunas preocupaciones". La primera de ellas es lo que él llama la "tendencia al docetismo" en la teología actual.

Lo que más me preocupa de la teología es su tendencia al docetismo, es decir, el crearse un ámbito propio de realidad que la distancie y desentienda de la realidad real, allá donde se hace presente el pecado y la gracia. Ese docetismo, que normalmente es inconsciente, puede muy bien llevar al aburguesamiento, es decir, a prescindir de los pobres y las víctimas que son mayoría en la realidad y son la realidad más flagrante ${ }^{34}$.

En realidad, el ambiente social y eclesial, poco favorable e incluso adverso a los procesos de liberación, y la tentación constante de la erudición, característica del mundo académico, han hecho que muchos teólogos se hayan distanciado de los procesos sociales y eclesiales, y hayan concentrado su actividad en el mundo de los libros y las teorías. Algunos de los discursos de esos teólogos son bastante progresistas, pero están desconectados de los procesos sociales y eclesiales y, por eso, son poco eficaces. Es el caso de gran parte de la teología europea. Más que "un momento del proceso a través del cual el mundo es transformado: abriéndose al don del reino de Dios", como proponía Gutiérrez ${ }^{35}$, la teología se va constituyendo como un mundo aparte, como escuela teológica, como movimiento de ideas, como sistema teórico, que vive de sí mismo y para sí mismo. "Abandona, así, lo que fue su intuición original: ser una reflexión que camina junto a la vida de la comunidad eclesial. La vida [...] precediendo y desafiando a la reflexión teológica"36.

34. J. Sobrino, "Teología desde la realidad", en L. C. Susin (coord.), O mar se abriu, pp. 153-170, aquí p. 168 (São Paulo: Loyola, 2000).

35. G. Gutiérrez, Teologia da libertação, op. cit., p. 74.

36. C. Palácio, "Trinta anos de teologia na América Latina: Um depoimento", en L. C. Susin (coord.), O mar se abriu, op. cit., pp. 51-64, aquí p. 60. 
Ya al comienzo de la década de 1980, el P. Arrupe, superior general de los jesuitas y muy próximo de la teología de la liberación, durante su visita a Centroamérica, afirmaba tener la impresión de que dicha teología "estaba perdiendo el push, que estaba volviéndose demasiado académica" ${ }^{37}$. Esto sin hablar de la tentación de la moda y la novedad cultural, con sus plateas y sus encuestas de opinión que, en la mejor de las hipótesis, relega a los pobres y los oprimidos, con sus sufrimientos y sus procesos de liberación, a cuestiones secundarias, que ya no despiertan el interés... Todos conocemos a teólogos progresistas desvinculados de los procesos sociales y eclesiales concretos, pero interesados en temas que consideran más actuales y más atractivos que la vida de los pobres y los oprimidos y sus procesos de liberación.

No se trata aquí de ningún tipo de "basismo", de pragmatismo o de activismo social o pastoral. Sino de tomar en serio algo determinante para el quehacer teológico: ser el momento inteligente de la fe o de la salvación y del reinado de Dios, cuya característica más importante es hacer justicia a los pobres y los oprimidos. Por tanto, debe estar constitutivamente ligado a los procesos sociales y eclesiales de liberación... Y eso en profunda sintonía con el proceso más amplio de renovación eclesial, que el papa Francisco propone e impulsa como "Iglesia en salida hacia las periferias".

El quehacer teológico también debe insertarse en ese proceso. La teología cristiana, en lo que tiene de intelección y en lo que tiene de servicio, debe ser siempre una teología en salida hacia las periferias del mundo, constituyéndose, en lo que le es propio y específico, en "signo e instrumento de salvación" para el mundo. Aquí se decide la densidad y la relevancia de la teología. En palabras certeras del papa Francisco: "Debemos guardamos de una teología que se agota en la disputa académica o que contempla la humanidad desde un castillo de cristal [...] También los buenos teólogos, como los buenos pastores, huelen a pueblo y a calle y, con su reflexión, derraman ungüento y vino en las heridas de los hombres".

El teólogo que la Iglesia necesita y debe formar "no [es] un teólogo "de museo', que acumula datos e información sobre la Revelación, pero sin saber muy bien qué hacer con ello. Y tampoco un 'balconero' de la historia". Debe ser "una persona capaz de construir en torno a sí la humanidad, de transmitir la divina verdad cristiana en una dimensión verdaderamente humana, y no un intelectual sin talento, un eticista sin bondad o un burócrata de lo sagrado"38.

37. Cfr. I. Ellacuría, "Iglesia en Centroamérica", en Escritos teológicos, II, op. cit., pp. 773-782, aquí p. 779.

38. Papa Francisco, Carta del Santo Padre Francisco al gran canciller de la Pontificia Universidad Católica Argentina en el centenario de la Facultad de Teología. 


\section{A modo de conclusión}

Esta reflexión nos coloca frente a un reto enorme: enfrentarnos teológicamente con la realidad en la cual estamos insertos y discernir allí los signos de los llamamientos salvíficos de Dios. Esta reflexión nos devuelve a la realidad y nos provoca para que nos enfrentemos con ella y la configuremos a partir y en función del reinado de Dios, cuyo criterio y medida permanente son los pobres y los marginados y sus resistencias y luchas.

Esto tiene muchas consecuencias para el quehacer teológico: (1) hacer y entender la teología como un momento de la fe de la Iglesia y del proceso más amplio de realización histórica de la salvación y del reinado de Dios; (2) ser consecuentes con el carácter histórico y parcial de esa salvación, superando toda forma de dualismo y universalismo abstracto; (3) insistir en la centralidad de los procesos históricos de liberación como signo y mediación privilegiados de la salvación y del reinado de Dios; (4) no desperdiciar el gran kairós que el ministerio pastoral del papa Francisco representa para la Iglesia y para el mundo, y colaborar con el proceso de renovación eclesial ("Iglesia en salida hacia las periferias del mundo") y, más concretamente, con el proceso de renovación teológica (teología en salida hacia las periferias del mundo); y (5) tomar en serio el hecho de que "fuera de los pobres, no hay salvación" y, en consecuencia, permanecer siempre unidos a ellos, en sus resistencias y sus luchas, y mantenernos siempre atentos y vigilantes para no caer en la tentación del "docetismo teológico".

Por eso, el carácter inconcluso, abierto y prospectivo de nuestra reflexión. Ella nos provoca, nos convoca y nos compromete. El reto está lanzado. La fidelidad y la creatividad de nuestros "padres y madres", en la vivencia de la fe y en el quehacer teológico, nos animan a emprender esta tarea. No huyamos del desafío de nuestra "hora". Es el tiempo y la situación que nos toca vivir y que el Señor confía a nuestra responsabilidad. Los pobres y los marginados son, en Él, jueces y señores de nuestras vidas y de nuestras teologías.

Disponible en https://w2.vatican.va/content/francesco/pt/letters/2015/documents/papafrancesco_20150303_lettera-universita-cattolica-argentina.html. 